\title{
Biodegradation of Wastewater Containing High Concentration of Sulfamethoxazole by Antibiotic Adopted Biofilm in Attached Growth Bioreactor
}

\author{
Nastaran Azimi', Amir Hessam Hassani ${ }^{1 *}$, Ghasem Najafpour Darzi², \\ Sayed Mehdi Borghei ${ }^{1}$
}

${ }^{1}$ Department of Environmental Engineering, Science and Research Branch, Islamic Azad University, Tehran, Iran ${ }^{2}$ Biotechnology Research Lab., Faculty of Chemical Engineering, Noshirvani University of Technology, Babol, Iran

Received: 20 October 2016

Accepted: 13 December 2016

\begin{abstract}
Pharmaceutical wastewater treatment is a complicated process due to the presence of various kinds of toxic chemicals and antibiotics that are harmful to any living organisms. In this study we employed a pilotscale net-like rotating biological contactor (NRBC) with three compartments and total volume of $78.75 \mathrm{~L}$ to eliminate high concentrations of sulfamethoxazole (SMX) from a synthetic wastewater. In this system, 16 plastic discs in each compartment were fixed on a horizontal shaft, rotating with constant speed (4 rpm). Activated sludge collected from a local hospital wastewater treatment plant was used as inoculum and the system was working in batch condition in order to develop adapted living organisms as biofilm on the rotation discs. Then the NRBC was successfully operated at continuous mode for 10 months at various organic loading rates (OLR) ( 0 to $21.3 \mathrm{gCOD} / \mathrm{L} . \mathrm{d}$ ), hydraulic retention times (HRT) (12 to $72 \mathrm{~h}$ ), and concentrations of sulfamethoxazole ( 5 to $120 \mathrm{mg} / \mathrm{L}$ ). It was found that by increasing in OLR and HRT, SMX removal efficiency was increased. Also, the obtained results indicated that increasing COD concentration had a positive impact on SMX removal efficiency, which was most probably due to the utilization of SMX as a nitrogen source. Finally, it was revealed that most SMX and organic matter removal occurred in the first compartment of the NRBC, and antibiotic concentration was negligible in the outlet stream.
\end{abstract}

Keywords: COD removal, NRBC, pharmaceutical wastewater, sulfamethoxazole degradation

\section{Introduction}

Pharmaceutical wastewater is known as highly polluting toxic effluent that includes large amounts of suspended solids and soluble organics [1]. The composition of these pollutants depends on the type of drug produced

*e-mail: ahhassani@srb.iau.ac.ir and the chemicals involved in downstream processing [2]. The existence of pharmaceutical and personal care products (PPCPs) in wastewater and water environment have been recognized all over the world [3-4].

Concerned about their potential risk, monitoring studies on their existence in the environment have been reported in literature [5], but few reports have discussed the exact fate of PPCPs in surface water and wastewater [6]. Experimental studies conducted in the last few decades 
have clearly revealed antibiotic contamination in aquatic environments [2]. This fact has increased public awareness and therefore it has received considerable attention in recent years. For example, contaminants such as organic matter and PPCPs exist in $80 \%$ of 139 U.S. streams [7] and their chemical effect, microbial persistence, and synergistic agents are still unknown [8]. Pharmaceutical residue enters the environment from several sources such as hospitals, pharmaceutical production industries, wastewater treatment plants (WWTPs), and landfills [9].

Pharmaceutical industrial wastewaters contain organic matter, raw substances, catalysts, chemical additives, reactants, and active pharmaceutical ingredients (APIs) [10]. Among PPCPs, antibiotics are a major problem for the environment because of their high consumption value in human health and veterinary medicine as well as widespread use as growth promoters for therapeutic goals [11]. Many antibiotics are hydrophilic so that they can be detected in surface water, groundwater, influent, and effluent of WWTPs in the range of a few $n g / L$ and $\mu \mathrm{g} / \mathrm{L}$ [12]. Antibiotics mostly enter the environment via diffuse agricultural input, landfill depletion, pharmaceutical industrial wastewaters, domestic wastewater (DWW), and WWTP effluents [13-15].

Sulfamethoxazole $\left(\mathrm{C}_{10} \mathrm{H}_{11} \mathrm{~N}_{3} \mathrm{O}_{3} \mathrm{~S}\right)$, a sulfonamide antibacterial, is a popular bacteriostatic antibiotic. Sulfamethoxazole is usually used in combination with trimethoprim at a ratio of 5:1 (as in co-trimoxazole, which is also known as Bactrim or Septra [11]). According to previous research, SMX is hardly biodegradable [16]. It has been reported that more than $50 \%$ of pharmaceutical wastewater is released without any treatment, and the existence of PPCPs in this wastewater lead to low efficiency in removal of chemical oxygen demand (COD) [17-18].

The most common and economical wastewater treatment approach is biological treatment [19]. The methods are frequently used in antibiotic removal consist of biological treatments such as conventional activate sludge (CAS), membrane bioreactor (MBR) in combination with methods like microfiltration (MF), ultrafiltration (UF), nanofiltration (NF) and reverse osmosis (RO), advanced oxidation processes (AOPs) and adsorption to activated carbon [20-24]. In several studies, MBR was considered a suitable alternative to CAS systems for antibiotic removal [1]. For example, similar efficiency in removal of erythromycin (ERY), clarithromycin (CLA), and trimethoprim (TMP) in both systems was reported. Although the removal of roxithromycin (ROX) is slightly desired in the CAS, MBR removal of sulfamethoxazole (SMX) is significantly better than by CAS. The removal of sulfamethoxazole in MBR and CAS were 95 and $60 \%$, respectively [25].

In Sweden, wastewater plants found a high rate of sorption to sludge for fluoroquinolones while reporting a slight removal of sulfamethoxazole and trimethoprim [26]. In 2004 Carballa et al. reported about 67\% removal efficiency in a Spanish WWTP for sulfamethoxazole, and the same results were achieved in sewage from different
Table 1. Removal efficiencies of sulfamethoxazole in different studies.

\begin{tabular}{|c|c|c|}
\hline Type of treatment system & $\begin{array}{c}\text { Removal efficiency } \\
\text { of SMX (\%) }\end{array}$ & Ref. \\
\hline $\begin{array}{c}\text { Biological treatment of } \\
\text { municipal wastewater }\end{array}$ & $50-90$ & {$[20]$} \\
\hline Sewage treatment plants & 40 & {$[26]$} \\
\hline $\begin{array}{c}\text { Municipal sewage treatment } \\
\text { plant }\end{array}$ & 60 & {$[27]$} \\
\hline Sewage treatment plants & 67 & {$[28]$} \\
\hline
\end{tabular}

wastewater treatment parts [27-28]. Furthermore, trimethoprim displays a high resistance to biodegradation in activated sludge treatment compared to sulfonamides [26]. The obtained results from these studies are summarized in Table 1.

Rotating biological contactor (RBC) is a system that contains a series of circular discs that rotate with a central horizontal shaft, and almost $40-45 \%$ of the entire disc surface area is immersed in wastewater [2930]. This system requires relatively little space and low capital cost for a treatment plant and disposal of sludge with easy construction, simple operation, low energy and maintenance costs, and resistance against sudden pollution load conditions [30]. Because of attached growth on the discs, a rotating biological contactor has high capacity to treat wastewater and decomposition of materials resistant to biodegradation. Furthermore, this system can tolerate hydraulic and organic load shocks [31].

In this study the biodegradation of SMX under aerobic conditions in a three-stage RBC system was investigated by an adapted enhanced culture of microorganisms. Also, the effect of HRT, OLR, and SMX concentration on RBC performance in removal of organic matter and antibiotics was assessed.

\section{Materials and Methods}

\section{Chemicals}

Sulfamethoxazole (analytical grade) was purchased from Chemidaru pharmaceutical company (Tehran, Iran) and all other chemicals were supplied by Merck (Darmstadt, Germany). The solid phase extraction cartridges (SPE) were purchased from Waters (HLB cartridges of 50 $\mathrm{mg})$. Millipore $(0.22$ and $0.45 \mu \mathrm{m})$ and Whatman $(0.7 \mu \mathrm{m})$ filters were used for filtration purposes. Acetonitrile, methanol, and water were HPLC-grade and purchased from Merck. Ultrapure water was prepared through a Milli-Q purification system (Millipore, Schwabach, Germany).

\section{Analytical Methods}

The samples were collected from different compartments of NRBC plus inlet and outlet streams (Fig. 1). The 
collected samples were settled before a COD test for 30 min. The COD analysis was carried out using dichromate reagent based on standard method using close reflux. The colorimetric method was developed at a wavelength of $600 \mathrm{~nm}$ by means of a spectrophotometer (2100 SERIES, UNICO, U.S.A.). Total suspended solids (TSS) were determined (APHA Standard Methods, 2005). $\mathrm{pH}$ was measured using a portable $\mathrm{pH}$ meter (HI 8224, Hanna, U.S.A.). SMX determination was carried out using HPLC (Smartline, Knauer, Germany) equipped with a UV/VIS detector, a four-channel pump, and an injection valve to which a $20 \mu \mathrm{l}$ sample loop was attached. Samples were injected using a $100 \mu \mathrm{l}$ syringe (Hamilton, Reno, Nevada, USA). The column was a Prontosil (C18 H column) that was $250 \mathrm{~mm}$ in length and $4.6 \mathrm{~mm}$ in diameter. Before HPLC analysis, all samples were treated by solid phase extraction techniques (Waters HLB cartridges of $50 \mathrm{mg}$ ). Thus, the sample should be free of organic solvent and inorganic matter that may harm the HPLC column. The mobile phase was made up of $87 \%$ buffer solution $\left(0.02 \mathrm{M} \mathrm{C}_{2} \mathrm{H}_{3} \mathrm{O}_{2} \mathrm{NH}_{4}\right.$ in ultra-purified water at $\left.\mathrm{pH}=6\right)$ with $13 \%$ acetonitrile. The flow rate was set at $1 \mathrm{~mL} / \mathrm{min}$ and the wavelength used for detection was $265 \mathrm{~nm}$ [11]. Additionally, all microorganism observations were done under a Nikon YS 100 microscope (Nikon, Japan).

\section{NRBC Setup}

A pilot-scale RBC in three compartments was madeup of $8 \mathrm{~mm}$ thick acrylic plastic sheets. Set-up dimensions were $75 \mathrm{~cm}$ long, $35 \mathrm{~cm}$ wide, and $30 \mathrm{~cm}$ deep. The schematic diagram for the fabricated RBC is shown in Fig. 1.

The discs, which were made of blue plastic sheet with thickness of $3 \mathrm{~mm}$, were fixed on a horizontal steel shaft. The shaft passed through the center of the discs and were rotated by an electric motor (NDRD Motor, Model SK 63/4, Germany) with constant rotational speed (4 rpm). The feed rate was controlled by a peristaltic pump (Etatron D.S., Model PDP-B-V, Italy) with changeable speed $(0-150 \mathrm{ml} / \mathrm{min})$.

\section{Composition of Synthetic Wastewater}

The feed was a synthetic wastewater consisting of sugar cane molasses $\left(\mathrm{C}_{6} \mathrm{H}_{12} \mathrm{O}_{3} \mathrm{NNaS}\right)$, commercial grade potassium hydrogen phosphate and potassium dihydrogen phosphate $\left(\mathrm{K}_{2} \mathrm{HPO}_{4}\right.$ and $\left.\mathrm{K}_{2} \mathrm{HPO}_{4}\right)$, and urea $\left(\mathrm{CH}_{4} \mathrm{~N}_{2} \mathrm{O}\right)$ with a ratio of $\mathrm{C}: \mathrm{N}: \mathrm{P}$ at 100:5:1. Experiments were conducted with different concentrations of synthetic feed and sulfamethoxazole. Activated sludge for inoculum was collected from the wastewater treatment plant of Valiasr Hospital (Qaemshar, Iran). The consortium of bacteria in the activated sludge was adapted to the presence of sulfamethoxazole in the RBC.

\section{Bioreactor Operation}

The NRBC system was first operated in batch mode for a duration of 20 days. The COD concentration of synthetic wastewater was increased from 600 to $8,000 \mathrm{mg} / \mathrm{l}$. At this period the system was run at HRT of

a)

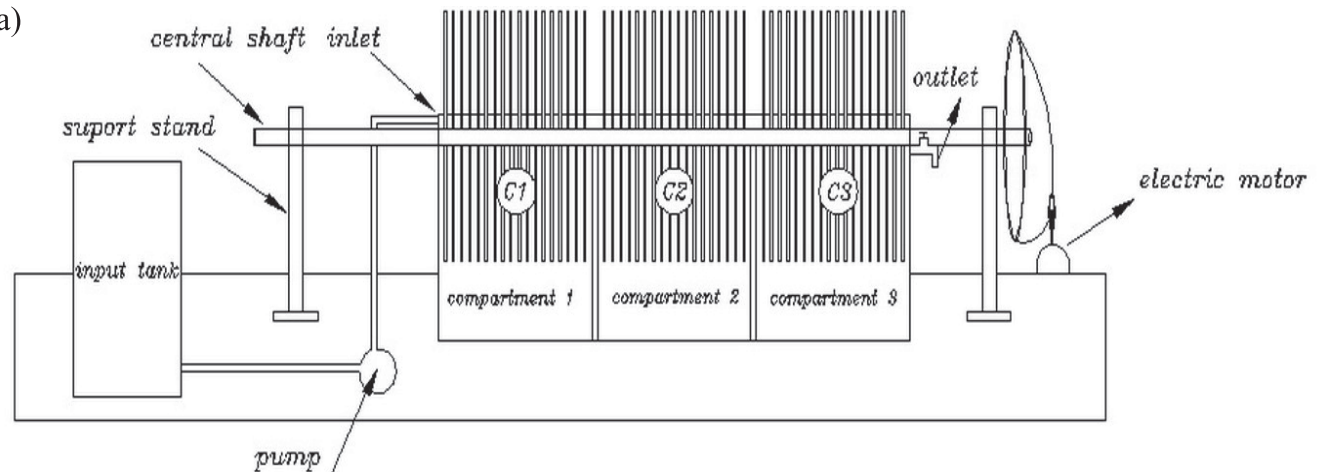

b)

c)
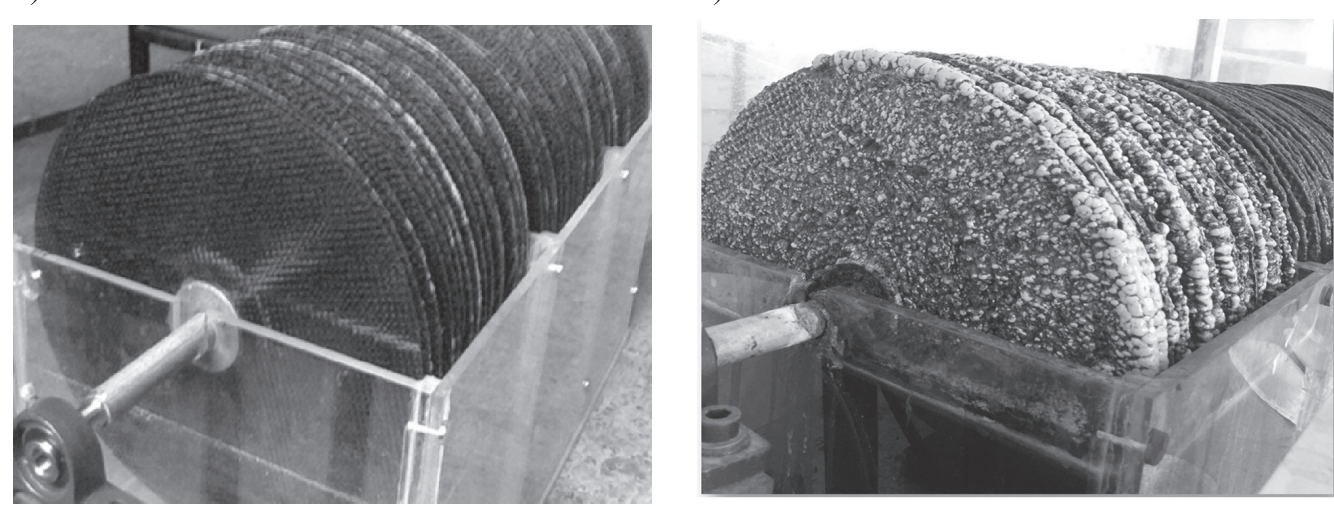

Fig. 1. a) Schematic diagram of the fabricated RBC, b) bare discs, and c) thick biofilm developed on the surface of discs. 
$24 \mathrm{~h}$ and the rotational speed of discs was fixed at $4 \mathrm{rpm}$. For the duration of the first week, considerable biofilm was developed on both sides of the discs and after 12 days the biofilm was fully developed (Fig. 1).

Then, the system was continuously operated for 10 months and in this period the NRBC was run at various HRT, COD, and SMX concentrations. Meanwhile, we investigated the effect of different influent CODs, SMXs, and HRTs, plus COD and SMX removal efficiencies on the NRBC system.

\section{Results and Discussions}

\section{Continuous COD Removal in the NRBC Reactor}

Before adding SMX, the NRBC was continuously operated at HRT of 12 to $60 \mathrm{~h}$ and the inlet COD concentrations were varied from 8,000 to $32,000 \mathrm{mg} / \mathrm{L}$ (OLR 2.7 to $21.3 \mathrm{~g} \mathrm{COD/L.d).} \mathrm{The} \mathrm{samples} \mathrm{were} \mathrm{collected}$ in three stages of the NRBC system. The obtained results indicated that by increasing HRT, COD removal was gradually increased. However, for HRT greater than $36 \mathrm{~h}$, there was no significant improvement in COD removal efficiency. The maximum COD removals using COD concentrations of $8,000 \mathrm{mg} / \mathrm{L}$ at various HRTs $(12,24,36$, 48 , and $60 \mathrm{~h}$ ) were $75,86,96,96.6$, and $97 \%$, respectively. In NRBC, the optimal HRT for desired rate of COD removal was $36 \mathrm{~h}$. So the optimal HRT for the desired rate of COD removal was considered to be $36 \mathrm{~h}$.

\section{Continuous COD Removal and SMX in the NRBC Reactor}

When the system reached a steady-state condition, antibiotic addition was performed in different concentrations of SMX and OLR.

Dosages of SMX in inlet flow were varied and in each dose the system was run for the duration, gradually reaching stable condition. The durations for each dose $(1,5,15$, $30,60$, and $120 \mathrm{mg} / \mathrm{L})$ to reach constant COD removal efficiency were different $(3,7,7,14,14$, and 14 days). The fluctuations in COD removal efficiency in low SMX concentrations ( 1 to $15 \mathrm{mg} / \mathrm{L}$ ) were negligible, and for this reason the required adaptation times were less than high concentrations of SMX (15 to $120 \mathrm{mg} / \mathrm{L})$.

Inlet COD concentration was $8,000 \mathrm{mg} / \mathrm{L}$, which is the usual average concentration in pharmaceutical industry wastewaters in Iran. In order to investigate the biodegradability of antibiotic as organic matter, the removal of SMX and COD were measured as SMX concentrations and HRTs were varied (Fig. 2). As expected, both COD and SMX concentrations were decreased by increasing HRTs. At optimal HRT (36 h) with different concentrations of SMX (from 5 to $120 \mathrm{mg} / \mathrm{L}$ ), the percentages of antibiotic removal gradually dropped from 80 to $62 \%$ as antibiotic concentrations increased. The results demonstrate that SMX biodegradation occurred before HRT of
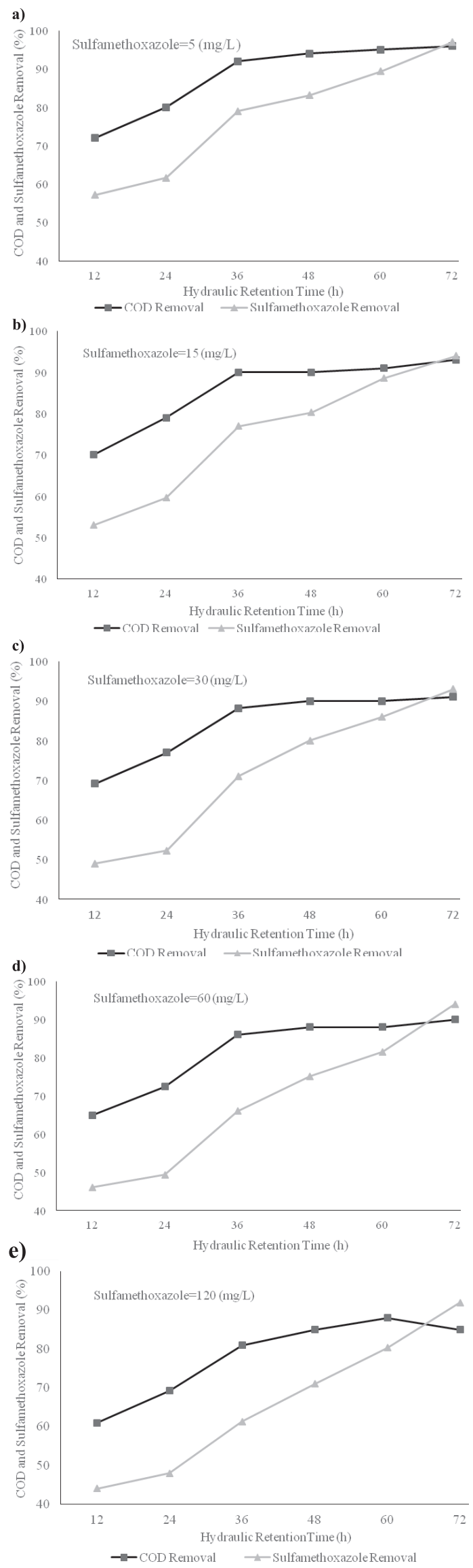

Fig. 2. Removal efficiencies for a) $5 \mathrm{mg} / \mathrm{L}$, b) $15 \mathrm{mg} / \mathrm{L}$, c) 30 $\mathrm{mg} / \mathrm{L}$, d) $60 \mathrm{mg} / \mathrm{L}$, and e) $120 \mathrm{mg} / \mathrm{L} \mathrm{SMX}$ and COD with respect to HRTs. 


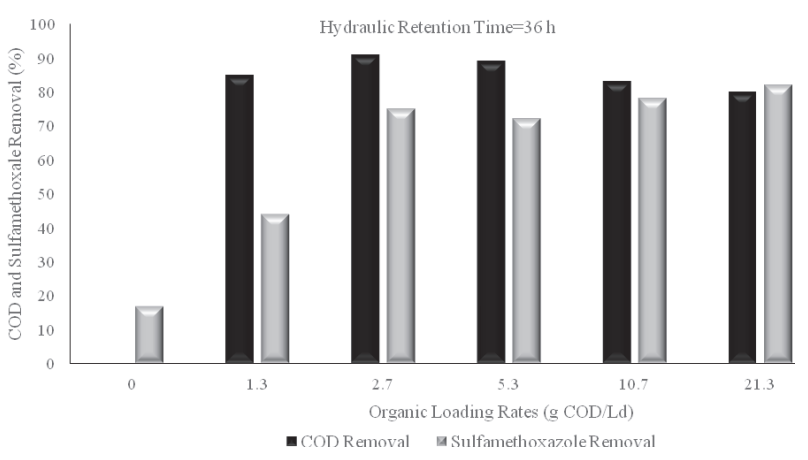

Fig. 3. Removal of SMX in various COD concentrations.

$60 \mathrm{~h}$. These results proved that microorganisms can gradually become adapted to new environmental and nutritional sources. Also, the figures exhibit that about $50 \%$ of SMX biodegradation was degraded in the first $12 \mathrm{~h}$; however, the majority of SMX elimination occurred within $72 \mathrm{~h}$. Moreover, as SMX concentration increased, antibiotic removal efficiency slightly decreased. For instance, when increasing SMX concentration from 5 to $120 \mathrm{mg} / \mathrm{L}$ at HRT of $60 \mathrm{~h}$, SMX removal efficiency decreased from 89.4 to $80.3 \%$.

In a similar research conducted on the treatment of domestic wastewater by an activated sludge system, SMX removal efficiency was reported to be $52 \%$. However, this value increased to $60 \%$ for an activated sludge system followed by a horizontal subsurface flow bed. These results indicate that the NRBC system in removal of antibiotics was more efficient than the activated sludge system, which was traditionally used in wastewater treatment plants [15].

We observed that morphology and general appearance of the attached biofilm as well as quantity of fungi and bacteria were significantly changed during the antibiotic removal process. The main reason for this change is the chemical shock, which resulted from the addition of antibiotics so that the fungi species became dominant in the biological film (as shown in Figure 1c) due to their higher resistance to antibiotics [32]. The fungi were identified by their mycelia under a microscope as well as silky macroscopic structure.

Moreover, we observed that the type of species of microorganism and overall biomass quantity were changed significantly from stage to stage. The fungi species were dominant in stage 1 and the biofilm thickness in this stage was also greater than the other stages, which is definitely due to the fact that the nutrients and antibiotic concentration were relatively higher in stage 1 than the other stages. These observations confirmed the results obtained from the similar research conducted by Su et al. [33].

\section{Impact of COD Concentration on SMX Removal}

In order to investigate the effect of COD concentration on SMX removal efficiency, antibiotic biodegradation was analyzed at HRT $=36 \mathrm{~h}$. To achieve this purpose the

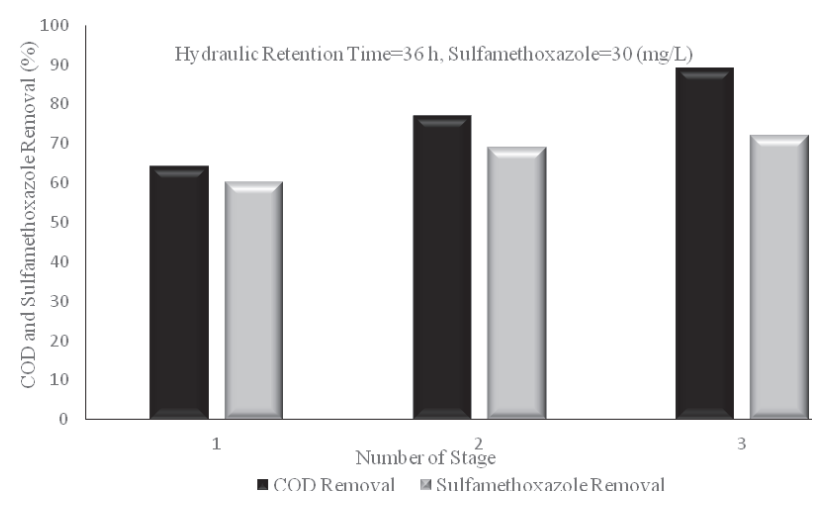

Fig. 4. SMX and COD removal efficiencies in each NRBC compartment.

inlet COD was changed from 0 to $32,000 \mathrm{mg} / \mathrm{L}$ in six steps, and SMX concentration was kept constant $(30 \mathrm{mg}$ per liter of inlet synthetic wastewater). Fig. 3 illustrates the obtained results, which proposed that SMX elimination was enhanced by increasing OLR. The SMX biodegradation trend was different with organic matter elimination. In other words, the higher COD concentrations led to more antibiotic removal efficiency. It seems that when there is willingness of degradable carbon sources, sulfamethoxazole served as a nitrogen source so that antibiotic removal efficiency enhanced with increasing COD concentrations.

\section{SMX and COD Removal Efficiency in Each Compartment of NRBC}

COD and SMX value in each compartment were analyzed separately for estimating the capability of the system in elimination of organic compounds, such as simultaneous antibiotic removal in each stage of NRBC at HRT $=36 \mathrm{~h}$ and SMX $=30 \mathrm{mg} / \mathrm{L}$. As Fig. 4 depicts, most removal efficiency in decomposition of both COD and SMX takes places in compartment 1 because microbial activity in the first stage is expected to be high, which is due to exposure of this compartment to the high nutrients.

\section{Conclusion}

In the present work, an attached growth bioreactor was employed for the treatment of wastewater containing a high concentration of sulfamethoxazole, and its capability in antibiotic removal was evaluated at different inlet COD and HRTs. SMX and COD removal efficiency in each compartment of NRBC was investigated separately. The obtained results indicate that high SMX removal efficiency takes place at various HRTs, and even at high organic load rates. In other words, in NRBC systems, enhancement of organic load rates not only did not have a deleterious effect on antibiotic elimination but also improved removal efficiency. The obtained results show that at optimal HRT, the percentages of antibiotic removal were gradually dropped from 80 to $62 \%$ as concen- 
trations of antibiotics increased. Also, by increasing SMX concentration from 5 to $120 \mathrm{mg} / \mathrm{L}$ at HRT of $60 \mathrm{~h}$, SMX removal efficiency decreased from 89.4 to $80.3 \%$. In addition, it was concluded that the most SMX removal efficiency occurred in the first compartment of the NRBC.

These results provide guidelines for employing the attached growth system instead of a traditionally used activated sludge system for the pharmaceutical industrial purpose; however, further studies are needed to investigate the performance of the RBC system in the elimination of other antibiotics.

\section{Acknowledgements}

The authors gratefully acknowledge Biotechnology Research Lab and Noushirvani University of Technology (Babol, Iran) for the support and facilities provided to conduct the present work

\section{References}

1. KAYA Y., ERSAN G., VERGILI I., GÖNDER Z. B., YILMAZ G., DIZGE N., AYDINER C. The treatment of pharmaceutical wastewater using in a submerged membrane bioreactor under different sludge retention times. J. Membrane Sci. 442, 72, 2013

2. OAKS J.L., GILBERT M., VIRANI M.Z., WATSON R.T., METEYER C.U., RIDEOUT B.A., SHIVAPRASAD H., AHMED S., CHAUDHRY M.J.I., ARSHAD M. Diclofenac residues as the cause of vulture population decline in Pakistan. Nature. 427 (6975), 630, 2004.

3. DEEGAN A., SHAIK B., NOLAN K., URELL K., OELGEMÖLLER M., TOBIN J., MORRISSEY A. Treatment options for wastewater effluents from pharmaceutical companies. Int .J Environ. Sci. Technol. 8 (3), 649, 2011.

4. ZHANG C., TANG J., WANG L., GAO X., HE X. Occurrence of antibiotics in water and sediment from Zizhuyuan Lake. Pol. J. Environ. Stud. 24 (4), 1831, 2015.

5. YUAN X., QIANG Z., BEN W., ZHU B., LIU J. Rapid detection of multiple class pharmaceuticals in both municipal wastewater and sludge with ultra high performance liquid chromatography tandem mass spectrometry. J. Environ.Sci. 26 (9), 1949, 2014

6. GÖBEL A., MCARDELL C. S., JOSS A., SIEGRIST H., GIGER W. Fate of sulfonamides, macrolides, and trimethoprim in different wastewater treatment technologies. Sci. Total. Environ. 372 (2), 361, 2007.

7. KOLPIN D.W., FURLONG E.T., MEYER M.T., THURMAN E.M., ZAUGG S.D., BARBER L.B., BUXTON H.T. Pharmaceuticals, hormones, and other organic wastewater contaminants in US streams, 1999-2000: A national reconnaissance. Environ. Sci. Technol. 36 (6), 1202,2002

8. MADUKASI E., DAI X., HE C., ZHOU J. Potentials of phototrophic bacteria in treating pharmaceutical wastewater. Int. J. Environ. Sci. Technol. 7 (1), 165, 2010.

9. LILLENBERG M., YURCHENKO S., KIPPER K., HERODES K., PIHL V., LÕHMUS R., IVASK M., KUU A., KUTTI S., LITVIN S. Presence of fluoroquinolones and sulfonamides in urban sewage sludge and their degradation as a result of composting. Int. J. Environ. Sci. Technol. 7 (2), 307, 2010.

10. SREEKANTH D., SIVARAMAKRISHNA D. HIMABINDU V., ANJANEYULU Y. Thermophilic treatment of bulk drug pharmaceutical industrial wastewaters by using hybrid up flow anaerobic sludge blanket reactor. Bioresource. Technol. 100 (9), 2534, 2009.

11. DRILLIA P., DOKIANAKIS S., FOUNTOULAKIS M., KORNAROS M., STAMATELATOU K., LYBERATOS $\mathrm{G}$. On the occasional biodegradation of pharmaceuticals in the activated sludge process: the example of the antibiotic sulfamethoxazole. J. Hazard. Mater. 122 (3), 259, 2005.

12. GOLET E.M., ALDER A.C., HARTMANN A., TERNES T.A., GIGER W. Trace determination of fluoroquinolone antibacterial agents in urban wastewater by solid-phase extraction and liquid chromatography with fluorescence detection. Anal. Chem. 73 (15), 3632, 2001.

13. JJEMBA P.K. The potential impact of veterinary and human therapeutic agents in manure and biosolids on plants grown on arable land: a review. Agr. Ecosyst. Environ. 93 (1), 267, 2002.

14. HEBERER T. Occurrence, fate, and removal of pharmaceutical residues in the aquatic environment: a review of recent research data. Toxicol. Lett. 131 (1), 5, 2002.

15. MÜLLER E., SCHÜSSLER W., HORN H., LEMMER $\mathrm{H}$. Aerobic biodegradation of the sulfonamide antibiotic sulfamethoxazole by activated sludge applied as co-substrate and sole carbon and nitrogen source. Chemosphere. 92 (8), 969, 2013

16. KÜMMERER K., ALEXY R., HÜTTIG J., SCHÖLL A. Standardized tests fail to assess the effects of antibiotics on environmental bacteria. Water Res. 38 (8), 2111, 2004.

17. ENICK O.V., MOORE M.M. Assessing the assessments: pharmaceuticals in the environment. Environ. Impact Assess. Rev. 27 (8), 707, 2007.

18. CHELLIAPAN S., WILBY T., SALLIS P.J. Performance of an up-flow anaerobic stage reactor (UASR) in the treatment of pharmaceutical wastewater containing macrolide antibiotics. Water Res. 40 (3), 507, 2006.

19. KULIK N., TRAPIDO M., GOI A., VERESSININA Y., MUNTER R. Combined chemical treatment of pharmaceutical effluents from medical ointment production. Chemosphere. 70 (8), 1525, 2008.

20. TERNES T., JOSS A. Human pharmaceuticals, hormones and fragrances-the challenge of micropollutants in urban water management. Water Intelligence Online. 5, 2006.

21. KRYVORUCHKO A.,YURLOVA L.Y. Impact of montmorillonate on the process of purification of waters containing uranium by ultra-and nanofiltration. J. Water. Chem. Technol. 38 (2), 96, 2016.

22. KORZH E., SMOLIN S., KLYMENKO N. Impact of characteristic of activated carbons on the efficiency of removal from water of pharmaceutical preparations of various chemical nature. J. Water. Chem. Technol. 38 (2), 83, 2016.

23. BEN W., QIANG Z., YIN X., QU J., PAN X. Adsorption behavior of sulfamethazine in an activated sludge process treating swine wastewater. J. Environ. Sci. 26 (8), 1623, 2014.

24. DOLAR D., VUKOVIC A., ASPERGER D., KOŠUTIC $\mathrm{K}$. Effect of water matrices on removal of veterinary pharmaceuticals by nanofiltration and reverse osmosis membranes. J. Environ. Sci. 23(8), 1299, 2011

25. SAHAR E., MESSALEM R., CIKUREL H., AHARONI A., BRENNER A., GODEHARDT M., JEKEL M., ERNST 
M. Fate of antibiotics in activated sludge followed by ultrafiltration (CAS-UF) and in a membrane bioreactor (MBR). Water Res. 45 (16), 4827, 2011.

26. LINDBERG R.H., WENNBERG P., JOHANSSON M.I., TYSKLIND M., ANDERSSON B.A. Screening of human antibiotic substances and determination of weekly mass flows in five sewage treatment plants in Sweden. Environ. Sci. Technol. 39 (10), 3421, 2005.

27. PÉREZ S., EICHHORN P., AGA D.S. Evaluating the biodegradability of sulfamethazine, sulfamethoxazole, sulfathiazole, and trimethoprim at different stages of sewage treatment. Environ. Toxicol. Chem. 24 (6), 1361, 2005.

28. CARBALLA M., OMIL F., LEMA J.M., LLOMPART M.A., GARCÍA-JARES C., RODRÍGUEZ I., GOMEZ M., TERNES T. Behavior of pharmaceuticals, cosmetics and hormones in a sewage treatment plant. Water Res. 38 (12), 2918, 2004.

29. NAJAFPOUR G., YIENG H.A., YOUNESI H., ZINATIZADEH A. Effect of organic loading on perfor- mance of rotating biological contactors using palm oil mill effluents. Process Biochem. 40 (8), 2879, 2005.

30. HIRAS D.N., MANARIOTIS I.D., GRIGOROPOULOS S.G. Organic and nitrogen removal in a two-stage rotating biological contactor treating municipal wastewater. Bioresource Technol. 93 (1), 91, 2004.

31. EBRAHIMI A., NAJAFPOUR G.D., MOHAMMADI M., HASHEMIYEH B. Biological treatment of whey in an UASFF bioreactor followed a three-stage RBC. Chem. Ind. Chem. Eng. Q. 16 (2), 175, 2010.

32. PRESCOTT L.M., HARLEY J.P., KLEIN D.A. Microbiology. Wm C Brown Publishers, 2005.

33. SU R., ZHANG G., WANG P., LI S., RAVENELLE R.M., CRITTENDEN J.C. Treatment of antibiotic pharmaceutical wastewater using a rotating biological contactor. J. Chem., 2015. 
